\title{
Acceptance of American society for gastrointestinal endoscopy's guidelines for endoscopy reports
}

\author{
Thomas de Lange ${ }^{1}$, Michael Bretthauer ${ }^{2}$, Lars Aabakken², Geir Hoff ${ }^{3,4}$ \\ ${ }^{1}$ Department of Internal Medicine, Section of Gastroenterology, Bærum Hospital, Sandvika, Norway \\ ${ }^{2}$ Department of Internal Medicine, Section of Gastroenterology, Oslo University Hospital, Oslo, Norway \\ ${ }^{3}$ Department of Internal Medicine, Section of Gastroenterology, Telemark Hospital, Skien, Norway \\ ${ }^{4}$ The University of Oslo, Oslo, Norway \\ Email: t.d.lange@medisin.uio.no
}

Received 2 July 2012; revised 13 August 2012; accepted 23 August 2012

\begin{abstract}
Background: Several studies indicate that endoscopy reports lack uniform content and terminology. Thus ASGE, ESGE, and WEO have prepared guidelines to improve the quality of endoscopy reports. However, the acceptance of such recommendations in the community of endoscopists has not been assessed. Objective: The aim of the present study was to determine Non-US endoscopists' agreement to current ASGE guidelines for endoscopy reporting and ESGE recommendations for image documentation. Design: 137 endoscopists were invited to participate in this internet survey, covering 34 items regarding the content of the endoscopy reports. Non-responders received three e-mail reminders before the study was closed. Settings: A web-based survey tool developed at the University of Oslo was used to perform this study (https://wo.uio.no/as/WebObjects/nettskjema.woa). Results: Eighty (60\%) of the 137 endoscopists responded, to the survey. Their agreement to the various items of the ASGE guidelines for text content ranged from $21 \%$ - 100\%. Only 8.9\% (95\% CI, $4.4 \%-17.2 \%)$ considered it necessary to perform routine image documentation according to the ESGE guidelines. Limitations: The response rate of $68 \%$, is on the lower limit of acceptable. Conclusions: The cohort of endoscopists agrees partially to the ASGE guidelines. However, they do not consider systematic image documentation necessary.
\end{abstract}

Keywords: Quality Assurance; Guideline Adherence; Gastrointestinal Endoscopy

\section{INTRODUCTION}

Gastrointestinal (GI) endoscopy is a fundamental diagnostic and therapeutic tool for evaluation and treatment of GI disorders [1-5]. The endoscopy reports are the primary tool for documentation and communication of findings, diagnosis, treatment, and recommendations for subsequent care and also serve important administrative and legal purposes. Thus, high quality and completeness of endoscopy reports are essential [6,7]. However, several studies indicate that endoscopy reports are incomeplete and lack uniform content and terminology [8,9]. Incomplete and erroneous reports might have serious impact to the patients' welfare and cause redundant examinations and reduced cost-benefit $[10,11]$.

As a part of an initiative to improve endoscopy reports, the American Society for Gastrointestinal Endoscopy (ASGE) Standards of Practice Committee have prepared guidelines for the contents of endoscopy reports [12] (Table 1). The European Society of Gastrointestinal Endoscopy (ESGE) Quality assurance Committee has generated recommendations for systematic image documentation [13] and the World Endoscopy Organization (WEO) has published a Minimum Standard Terminology (MST) [14-17]. These guidelines aim to make the reports more complete, standardized and objective. The applications of the guidelines in clinical practice may also permit continuous auditing and comparison of the activity in endoscopy units.

There is an increasing number of guidelines in all medical fields and there exist several barriers influencing physicians compliance to guidelines [18]. However, common acceptance of the guidelines is an important prerequisite for their application. Therefore we aimed to assess the acceptance of the ASGE guidelines for endoscopy reports in a cohort of Non-US endoscopists, and to assess which variables the cohort estimated necessary to record in the endoscopy reports. Furthermore, we wished to determine their acceptance of ESGE recommendations for image documentation. The acceptance to record some other widely-used quality indicators was also assessed. To our knowledge, the acceptance of guidelines for quality improvement in GI endoscopy have never been tested 
Table 1. Items to be recorded according to ASGE guidelines for endoscopy reports [12].

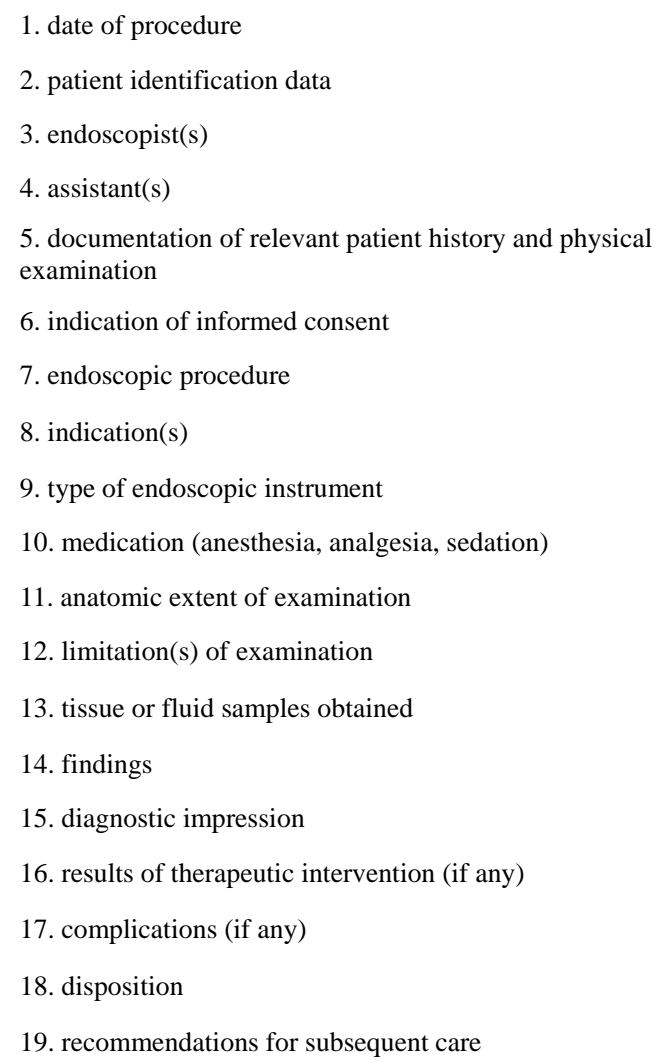

before in a cohort of endoscopists.

\section{MATERIALS AND METHODS}

An e-mailing list including 137 experienced endoscopists, based upon two congress registries, the mailing list of the Norwegian part of Scandinavian Association of Digestive Endoscopy and personal mailing lists were used to invite endoscopists to participate in this survey. Nonresponders received three e-mail reminders before the study was closed.

A web-based survey tool developed at the University of Oslo was used to perform this study

(https://wo.uio.no/as/WebObjects/nettskjema.woa). A total of 34 items were addressed, of which 25 concerned the ASGE guidelines, 1 concerned the ESGE guidelines for photo documentation, and 8 questions dealt with administrative, widely-used quality indicators and present and future documentation system issues. The assessed items were (items included in ASGE recommendations marked with").

\subsection{Medico-Legal Mandatory Items}

Patient name ${ }^{\#}$, date of birth ${ }^{\#}$, date of procedure ${ }^{\#}$, and name of endoscopist".

\subsection{Medical Record Data}

Reason for the examination", relevant medical history", medical history specified into past and present, physical examination ${ }^{\#}$, treatment recommendations ${ }^{\#}$ and follow up .

\subsection{Technical Items}

Technical limitations ${ }^{\#}$ with the additional specifications "technical difficulties to perform the examination", "time to reach the duodenum/cecum", "time spent on the examination", "quality of bowel preparation", "use of fluoroscopy/SopeGuide ${ }^{\mathrm{TM}}$ (Olympus Corporate Tokyo, Japan) in colonoscopy”.

\subsection{Recording of Staff Identity}

Name of the assistants.

\subsection{Documentation Systems}

Present text and image documentation system, and the endoscopists' consideration regarding future systems for text and image documentation.

\subsection{Statistical Analysis}

The results are expressed as mean percentages with 95\% confidence intervals constructed by using the Student procedure [19]. The analysis was performed with JMP statistical package from SAS (SAS Institute, Cary, NC, USA).

\section{RESULTS}

$80(60 \%)$ of the 137 endoscopists responded. $90 \%(95 \%$ CI 81 - 96) of the responders considered the endoscopic appointment to be a complete or partial consultation at a GI specialist's and not only a technical examination.

\subsection{Medico-Legal Mandatory Items}

All responders agreed the medico-legally mandatory items to be included in the medical record (patient name", date of birth", date of procedure ${ }^{\#}$, and name of endoscopist ${ }^{\#}$ ). However, (10\%, 95\% CI 5 - 19) did not agree that the personal national ID number usually used to identify Norwegian individuals should be included.

\subsection{Medical History, Physical Examination and Recommendations}

The vast majority $81 \%$ - $100 \%$ of endoscopists considered the reason for the examination ${ }^{\#}$, previous medical history, actual medical history, and advice given on treatment and follow-up to be included in the endoscopy report (Figure 1). However, there were divergent opin- 


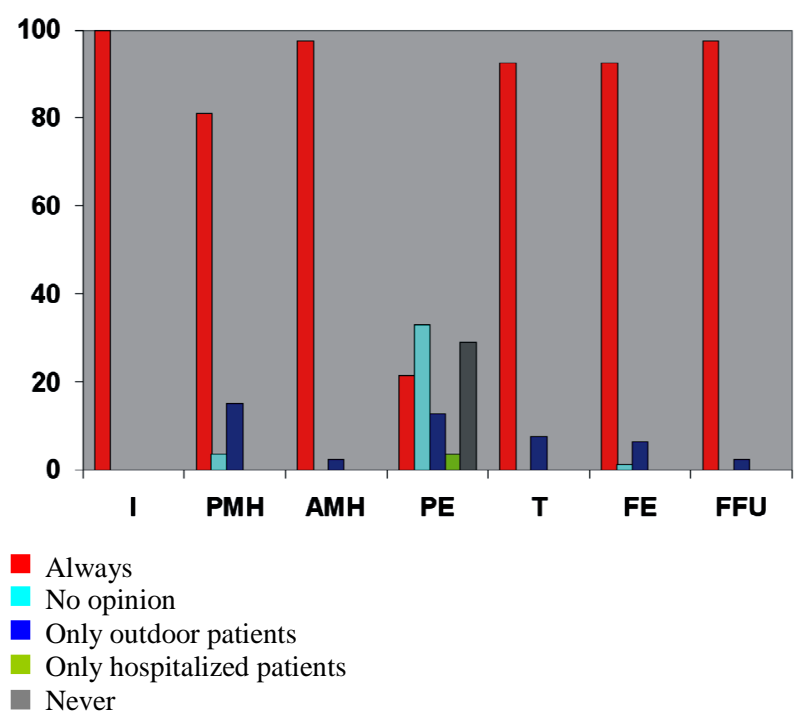

Figure 1. Necessity of reporting items of medical history and dispositions, computed as percentages of endoscopists replying to the different answer categories $(\mathrm{n}=80)$. $\mathrm{I}=$ indication, $\mathrm{PME}$ = previous medical history, $\mathrm{AMH}=$ actual medical history, $\mathrm{PE}$ $=$ physical examination, $\mathrm{T}=$ medical treatment, $\mathrm{FE}=$ further examinations, FFU = further follow up.

ions on the need for documenting physical examination ${ }^{\#}$ with only $22 \%$ (95\% CI, 14 - 32) saying that it should always be documented (Figure 2).

\subsection{Medication}

$76 \%$ (95\% CI 66 - 84) of the responders agreed that the use of pre-medication should always be recorded, whereas 24\% (95\% CI 16 - 35) considered that this should only be recorded if pre-medication has been administrated.

\subsection{Technical Items}

$48 \%$ (95\% CI 37 - 59) consider it necessary to always record technical limitations ${ }^{\#}$ to upper GI endoscopy (Figure 2). In contrast, 66\% (95\% CI 55 - 75) considered it necessary to record this variable for colonoscopy (Figure 3).

\subsection{Text Documentation}

At present, 63\% (95\% CI 52 - 73) of the endoscopists generate their endoscopy reports in a dictated free-text system, 35\% (95\% CI 26 - 46) in a semi-structured computer-based system and $1 \%(95 \% \mathrm{CI}, 0-7)$ in a structured menu-driven system. However, 85\% (95\% CI, 75 - 91) consider that a menu-driven semi-structured system would be most appropriate in the future.

\subsection{Image Documentation}

The vast majority of endoscopists have some sort of im-

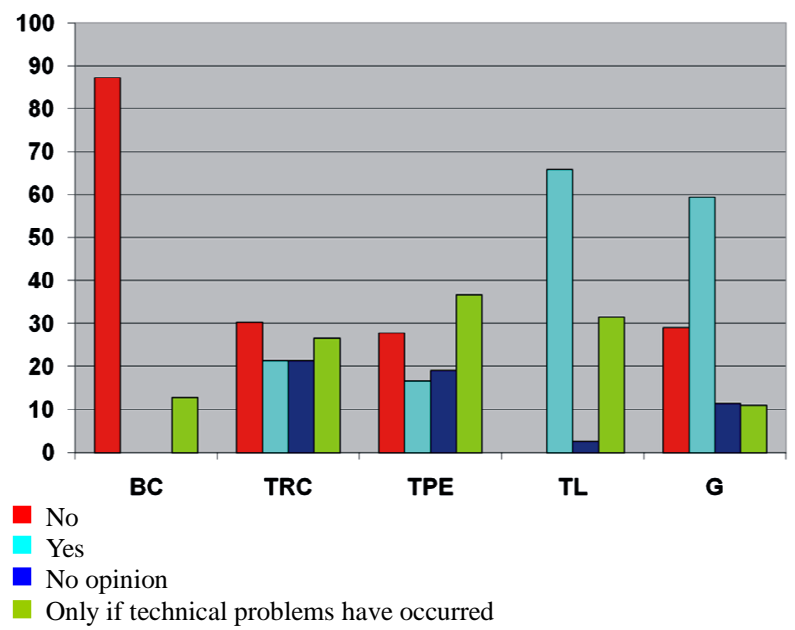

Figure 2. Percentages of endoscopists estimating the necessity of reporting technical items of the colonoscopy $(n=80)$. $\mathrm{BC}=$ bowel cleansing, $\mathrm{TRC}=$ time to reach cecum, $\mathrm{TPE}=$ total time to perform examination, $\mathrm{TL}=$ technical limitations, $\mathrm{G}=$ use of external guide (SopeGuide ${ }^{\mathrm{TM}}$ or fluoroscopy).

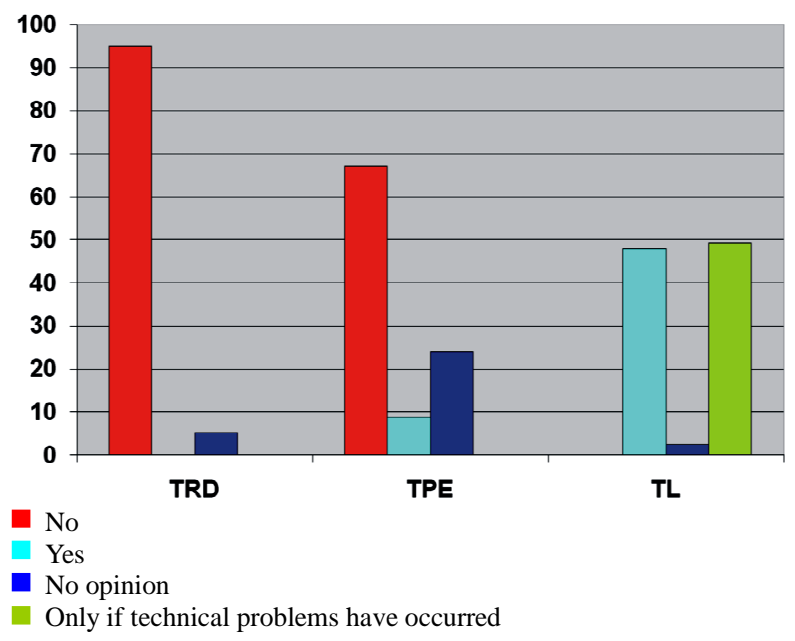

Figure 3. Percentages of endoscopists estimating the necessity of reporting technical items in upper GI endoscopy ( $\mathrm{n}=$ 80). TRD = time to reach duodenum, TPE = total time to perform examination, $\mathrm{TL}=$ technical limitations.

age documentation modality; 82\% (95\% CI 72 - 89) photo printer, 36\% (95\% CI 27 - 47) VHS reorder. However, only 9\% (95\% CI 4 - 17) considered it necessary to perform image documentation routinely, $4 \%$ (95\% CI, 1 - 11) did not have any opinion, and 87\% (95\% CI 78 - 93) considered it necessary only if pathologic findings were detected.

\subsection{Staff Identification}

All responders considered it necessary to record the name of the endoscopist ${ }^{\#}$ in the report. However, even if it is recommended to record the name of the assistant ${ }^{\#}$, only 23\% (95\% CI, 15 - 33) of the endoscopists consid- 
ered it necessary.

\section{DISCUSSION}

Mainly, this cohort of Non-US endoscopists agrees to current ASGE guidelines for endoscopy reports concerning medical information items, except for the need to record findings of the physical examination. However, technical items are considered less important, particularly in upper GI endoscopy. There was poor acceptance of the ESGE guidelines for systematic image documentation. This may be related to the endoscopists' limited access to electronic systems for image documentation.

The study has some limitations; the response rate of $60 \%$, on the lower limit of acceptable, may be due to limited in-hospital Internet access and to the limited possibility of only inviting physicians performing endoscopy on a regular basis.

However, we believe that the cohort is representative of Norwegian endoscopists, but we are not able to exclude bias in terms of non-representative proportions of surgeons/medical gastroenterologists, older/younger endoscopists, academic/non-academic endoscopists.

Variables like the time spent to reach the cecum and total examination time (and subsequently withdrawal time); cecum intubation rate and quality of bowel cleansing are widely-used quality indicators in colonoscopy [20-24]. Interestingly, as shown in Figure 2, many endoscopists in the present survey did not consider these variables to be important to be recorded. This may reflect an inadequate level of consciousness towards accepted quality indicators, or a conscious neglect if the endoscopists consider these indicators not to measure quality. Also, it has to be considered that exposure of suboptimal performance may be a personal threat to some. Obviously, education and debate regarding the establishment and implementation of quality indicators in colonoscopy is necessary in the future.

There is an increasing focus on the efficiency and quality of medical care. Medical records, including endoscopy reports play a fundamental role to reach this goal and perform high quality care [20,25]. Recent works of ASGE, ESGE and WEO to standardize the endoscopy reports are important initiatives to reach this goal. This standardization may also make international multicentre collaboration, comparison, audits and quality assurance easier [26-32]. These guidelines do, however, need continuous updating to include recently determined quality indicators, e.g. withdrawal time during colonoscopy, which has been shown to significantly affect the detection rate of colonic polyps [33-37].

It is estimated that related to endoscopic activity, 400 variable data fields are generated for every procedure [38]. However, it is a challenge only to record items required to secure high quality care and cost-effectiveness.
We estimated that the results of the survey would be influenced by how endoscopists consider the role of the endoscopic examination. However, one has also to keep in mind that the vast majority of endoscopic examinations in Norway are performed on an open access basis. Interestingly, the vast majority of participants consider the endoscopic examination as a specialist consultation requiring the same medical decision-making as any other specialist consultation. This may explain why the respondents in the present trial nearly fully agree to ASGE guidelines regarding the medical history of the patient. However, only 25\% considered that it is required to document findings of an eventually physical examination.

In the present study, endoscopists considered medical information more important than administrative information. However, the importance of such information is probably increasing because it might be an important tool to organize the ward cost-effectively.

At present, a majority of endoscopists use transcription based free-text. Nevertheless, a vast majority consider that computerized systems will be the most appropriate tool in the future, indicating that physician skepticism towards these systems is limited. This fact is supported by studies showing that data entry in structured systems is fast, complete and well accepted [39-45].

A major advantage of structured CEMR is the automatic generation of databases. Thus, automatic coding for e.g. ICD and NCSP may also be implemented.

Norwegians endoscopists do not support the ESGE's recommendations for systematic image documentation, even if it probably would render the reports more objective. Partially, this might be explained by cumbersome image documentation systems in most endoscopy units today. However, the compliance to these recommendations might improve by implementation of more userfriendly and efficient image documentation systems. The quality issue of photographic documentation has been an issue particularly in radiology for about ten years [46-48]. With competitive imaging methods like CT colonography coming up, this issue should no longer be neglected in gastrointestinal endoscopy.

\section{CONCLUSION}

The present survey has shown that this cohort of endoscopists is mainly in favor of more standardized and structured reporting systems.

\section{REFERENCES}

[1] American So- ciety for Gastrointestinal Endoscopy (1998) The role of colonoscopy in the management of patients with inflammatory bowel disease. Gastrointestinal Endoscopy, 48, 689-690. 


\section{doi:10.1016/S0016-5107(98)70062-8}

[2] Ullman, T., Odze, R. and Farraye, F.A. (2009) Diagnosis and management of dysplasia in patients with ulcerative colitis and Crohn's disease of the colon. Inflammatory Bowel Diseases, 15, 630-638. doi:10.1002/ibd.20766

[3] De, B.V., Gonvers, J.J., Froehlich, F., Dubois, R.W., Burnand, B. and Vader, J.P. (1999) Appropriateness of gastroscopy: Bleeding and dysphagia. Endoscopy, 31, 615622. doi:10.1055/s-1999-65

[4] Chan, Y.M. and Goh, K.L. (2004) Appropriateness and diagnostic yield of EGD: A prospective study in a large Asian hospital. Gastrointestinal Endoscopy, 59, 517-524. doi:10.1016/S0016-5107(04)00002-1

[5] Rutegard, J.N. (1993) Assessment profiles of disease severity in ulcerative colitis. Digestive Disease, 11, 32-35. doi:10.1159/000171398

[6] Pfeil, S.A. (1994) The upper gastrointestinal endoscopy report. Gastrointestinal Endoscopy Clinics of North America, 4, 541-550.

[7] de Lange, T., Moum, B.A., Tholfsen, J.K., Larsen, S. and Aabakken, L. (2003) Standardization and quality of endoscopy text reports in ulcerative colitis. Endoscopy, 35, 835-840. doi:10.1055/s-2003-42619

[8] Nelson, D.B., Block, K.P., Bosco, J.J., Burdick, J.S., Curtis, W.D., Faigel, D.O., et al. (2000) Technology status evaluation report: Computerized endoscopic medical record systems: November 1999. Gastrointestinal Endoscopy, 51, 793-796. doi:10.1053/ge.2000.v51.age516793

[9] Moorman, P.W., van Ginneken, A.M., van der, L.J., Siersema, P.D., van Blankenstein, M. and Wilson, J.H. (1994) The contents of free-text endoscopy reports: An inventory and evaluation by peers. Endoscopy, 26, 531538. doi:10.1055/s-2007-1009029

[10] Robertson, D.J., Lawrence, L.B., Shaheen, N.J., Baron, J.A., Paskett, E., Petrelli, N.J., et al. (2002) Quality of colonoscopy reporting: A process of care study. The American Journal of Gastroenterology, 97, 2651-2656. doi:10.1111/j.1572-0241.2002.06044.X

[11] Conway, J.D., Adler, D.G., Diehl, D.L., Farraye, F.A., Kantsevoy, S.V., Kwon, R., et al. (2008) Endoscopic electronic medical record systems. Gastrointestinal Endoscopy, 67, 590-594. doi:10.1016/j.gie.2008.01.040

[12] American Society for Gastrointestinal Endoscopy (1999) Quality improvement of gastrointestinal endoscopy: Guidelines for clinical application. Gastrointestinal Endoscopy, 49, 842-844. doi:10.1016/S0016-5107(99)70315-9

[13] Rey, J.F. and Lambert, R. (2001) ESGE recommendations for quality control in gastrointestinal endoscopy: Guidelines for image documentation in upper and lower GI endoscopy. Endoscopy, 33, 901-903.

[14] Delvaux, M. and Korman, L.Y. (2000) Minimal standard terminology in digestive endoscopy. Endoscopy, 32, 162188. doi:10.1055/s-2000-7384

[15] Aabakken, L., Rembacken, B., LeMoine, O., Kuznetsov, K., Rey, J.F., Rosch, T., et al. (2009) Minimal standard terminology for gastrointestinal endoscopy-MST 3.0. Endoscopy, 41, 727-728.

[16] Crespi, M., Delvaux, M., Schaprio, M., Venables, C. and
Zwiebel, F. (1996) Working party report by the committee for minimal standards of terminology and Documentation in digestive endoscopy of the european society of gastrointestinal endoscopy. Minimal standard terminalogy for a computerized endoscopic database. Ad hoc task force of the committee. American Journal of Gastroenterology, 91, 191-216.

[17] Delvaux, M., Korman, L.Y., Armengol-Miro, J.R., Crespi, M., Cass, O., Hagenmuller, F., et al. (1998) The minimal standard terminology for digestive endoscopy: Introduction to structured reporting. International Journal of Medical Informatics, 48, 217-225. doi:10.1016/S1386-5056(97)00128-7

[18] Cabana, M.D., Rand, C.S., Powe, N.R., Wu, A.W., Wilson, M.H., Abboud, P.A., et al. (1999) Why don’t physicians follow clinical practice guidelines? A framework for improvement. The Journal of the American Medical Association, 282, 1458-1465. doi:10.1001/jama.282.15.1458

[19] Altman, D.G. (1991) Practical statistics for medical research. Chapman and Hall, London.

[20] Hoff, G., Bretthauer, M., Huppertz-Hauss, G., Kittang, E., Stallemo, A., Hoie, O., et al. (2006) The Norwegian Gastronet project: Continuous quality improvement of colonoscopy in 14 Norwegian centres. Scandinavian Journal of Gastroenterology, 41, 481-487. doi:10.1080/00365520500265208

[21] Barclay, R.L., Vicari, J.J., Doughty, A.S., Johanson, J.F. and Greenlaw, R.L. (2006) Colonoscopic withdrawal times and adenoma detection during screening colonoscopy. The New England Journal of Medicine, 355, 25332541. doi:10.1056/NEJMoa055498

[22] Johanson, J.F., et al. (2000) Quality and outcomes assessment in gastrointestinal endoscopy. Gastrointestinal Endoscopy, 5, 827-830. doi:10.1016/S0016-5107(00)70218-5

[23] Lieberman, D.A., Faigel, D.O., Logan, J.R., Mattek, N., Holub, J., Eisen, G., et al. (2009) Assessment of the quality of colonoscopy reports: Results from a multicenter consortium. Gastrointestinal Endoscopy, 69, 645-653. doi:10.1016/j.gie.2008.08.034

[24] Simmons, D.T., Harewood, G.C., Baron, T.H., Petersen, B.T., Wang, K.K., Boyd-Enders, F., et al. (2006) Impact of endoscopist withdrawal speed on polyp yield: Implications for optimal colonoscopy withdrawal time. Alimentary Pharmacology \& Therapeutics, 24, 965-971. doi:10.1111/j.1365-2036.2006.03080.x

[25] Savides, T.J., Chang, K. and Cotton, P. (2004) Possible features of current electronic endoscopic information systems: What to look for. Gastrointestinal Endoscopy Clinics of North America, 14, 735-743. doi:10.1016/j.giec.2004.05.005

[26] Eisen, G.M. (1999) Endoscopic databases and outcomes research. Gastrointestinal Endoscopy Clinics of North America, 9, 587-594.

[27] Sivak, M.V., Jr. (2000) Endoscopy databases and endoscopic research. Gastrointestinal Endoscopy, 51, 243-244. doi:10.1016/S0016-5107(00)70434-2

[28] Cooper, G. and Sivak, M.V., Jr. (2000) More on endo- 
scopy databases. Gastrointestinal Endoscopy, 51, 759-761. doi:10.1067/mge.2000.106313

[29] Minoli, G., Meucci, G., Prada, A., Terruzzi, V., Bortoli, A., Gullotta, R., et al. (1999) Quality assurance and colonoscopy. Endoscopy, 31, 522-527. doi:10.1055/s-1999-54

[30] Korman, L.Y. (1999) Standardization in endoscopic reporting: Implications for clinical practice and research. Journal of Clinical Gastroenterology, 28, 217-223. doi:10.1097/00004836-199904000-00006

[31] Kruss, D.M. and Watkins, J.L. (1993) Computer programs in gastrointestinal endoscopy: Issues, problems, and solutions. Gastroenterologist, 1, 185-191.

[32] Maratka, Z. (1983) Toward a better endoscopic terminalogy. Gastrointestinal Endoscopy, 29, 136-137. doi:10.1016/S0016-5107(83)72554-X

[33] Rex, D.K. (2000) Colonoscopic withdrawal technique is associated with adenoma miss rates. Gastrointestinal Endoscopy, 51, 33-36. doi:10.1016/S0016-5107(00)70383-X

[34] Armstrong, D., Hollingworth, R., Macintosh, D., Chen, Y., Daniels, S., Gittens, S., et al. (2011) Point-of-care, peer-comparator colonoscopy practice audit: The Canadian association of gastroenterology quality programEndoscopy. Canadian Journal of Gastroenterology, 25, 13-20.

[35] Atkin, W., Rogers, P., Cardwell, C., Cook, C., Cuzick, J., Wardle, J., et al. (2004) Wide variation in adenoma detection rates at screening flexible sigmoidoscopy. Gastroenterology, 126, 1247-1256. doi:10.1053/j.gastro.2004.01.023

[36] Douglas, K., et al. (2006) Quality indicators for colonoscopy. The American Journal of Gastroenterology, 101, 873-885.

[37] Rex, D.K., Petrini, J.L., Baron, T.H., Chak, A., Cohen, J., Deal, S.E., et al. (2006) Quality indicators for colonoscopy. The American Journal of Gastroenterology, 101, 873-885.

[38] Weinstein, M.L. and Korman, L.Y. (2002) Information management. Gastrointestinal Endoscopy Clinics of North America, 12, 313-324. doi:10.1016/S1052-5157(01)00012-5

[39] Stoltzing, H., Birkner, B., Lindlar, R., Ohmann, C., Zaczyk, R., Kuntzen, O., et al. (1989) Computer-assisted docu- mentation in upper gastrointestinal endoscopy: Experiences with routine use at 3 clinics. Zeitschrift für Gastroenterologie, 27, 667-675.

[40] Soekhoe, J.K., Groenen, M.J., van Ginneken, A.M., Khaliq, G., Lesterhuis, W., van Tilburg, A.J., et al. (2007) Computerized endoscopic reporting is no more time-consuming than reporting with conventional methods. European Journal of Internal Medicine, 18, 321-325. doi:10.1016/j.ejim.2007.04.001

[41] Sackmann, M., Rosette, R., Busl, T., Sauter, G., Fischer, G., Hengstenberg, T., et al. (1998) A scientific relational database combined with a report generator for endoscopy in networks: EndoNet. Endoscopy, 30, 610-616. doi:10.1055/s-2007-1001365

[42] Gouveia-Oliveira, A., Raposo, V.D., Salgado, N.C., Almeida, I., Nobre-Leitao, C. and de Melo, F.G. (1991) Longitudinal comparative study on the influence of computers on reporting of clinical data. Endoscopy, 23, 334337. doi:10.1055/s-2007-1010710

[43] Kuhn, K., Gaus, W., Wechsler, J.G., Janowitz, P., Tudyka, J., Kratzer, W., et al. (1992) Structured reporting of medical findings: Evaluation of a system in gastroenterology. Methods of Information in Medicine, 31, 268274.

[44] Aabakken, L., Westerheim, J., Hofstad, B., Larsen, S. and Osnes, M. (1991) SADE database for endoscopic procedures: Aspects of clinical use. Endoscopy, 23, 269-271. doi:10.1055/s-2007-1010684

[45] Jacob, U., Foerster, E.C., Stettin, J., Schubbe, H., Domschke, W. (1994) Structured documentation in gastroscopy: A method for improved quality assurance? Zeitschrift für Gastroenterologie, 32, 514-518.

[46] Irvine, D. (1997) The performance of doctors. II: Maintaining good practice, protecting patients from poor performance. British Medical Journal, 314, 1613-1615. doi:10.1136/bmj.314.7094.1613

[47] Irvine, D. (1997) The performance of doctors. I: Professionalism and self regulation in a changing world. British Medical Journal, 314, 1540-1542. doi:10.1136/bmj.314.7093.1540

[48] Thomas, R.D., Fairhurst, J.J. and Frost, R.A. (1995) Wessex regional radiology audit: Barium enema in colorectal carcinoma. Clinical Radiology, 50, 647-650. doi:10.1016/S0009-9260(05)83297-0

\section{ABBREVIATIONS}

$\begin{array}{ll}\text { ASGE } & \text { American Society for Gastrointestinal Endoscopy } \\ \text { CEMR } & \text { Computerized Endoscopic Medical Record } \\ \text { ESGE } & \text { European Society of Gastrointestinal Endoscopy } \\ \text { GI } & \text { Gastrointestinal } \\ \text { ICD } & \text { International Classification of Diseases } \\ \text { MST } & \text { Minimum Standard Terminology } \\ \text { NCSP } & \text { NOMESKOS' Classification of Surgical Procedure } \\ \text { WEO } & \text { World Endoscopy Organization }\end{array}$

